Reprinted with permission from: Weed Technology. 1988. (2):132-138.

Published and copyrighted by: Weed Science Society of America. http://www.wssa.net

\title{
Population modeling approach for evaluating leafy spurge (Euphorbia esula) development and control ${ }^{1}$
}

\author{
BRUCE D. MAXWELL, MARK V. WILSON, and STEVEN R. RADOSEVICH \\ The authors are Grad. Res. Asst., Dep. For. Sci.; Asst. Prof., Dep. Bot Plant Pathol.; and Prof., Dep. For. Sci., Oreg. \\ State Univ., Corvallis, OR 97331, respectively.
}

\begin{abstract}
:
Weed population models can serve as a framework to organize weed biology information and to develop weed control strategies. Models help to identify information gaps, to set research priorities, to develop hypotheses pertinent to weed population regulation, and to suggest control strategies. A population simulation model of leafy spurge (Euphorbia esula L. \# EPHES) was used to demonstrate the applicability of population models to weed science. Sensitivity analysis of an existing leafy spurge model indicated that transition from basal buds to vegetative shoots, survival of vegetative shoots, and survival of basal buds over winter were important transition parameters influencing population growth of this weed species. Possible mechanisms (intraspecific competition and environmental factors) that influence the transition from basal buds to vegetative shoots were shown. Intraspecific density effects on basal bud transition and production were included to show model refinement and second-generation model development. Four control strategies were simulated and were compared to field studies to show the predictive and management potential of the modeling approach. Simulations of population response to foliage feeding herbivores was highly correlated $(\mathrm{r}=0.98)$ with field data for sheep grazing on leafy spurge. Simulation of picloram (4-amino-3,5,6trichloro-2-pyridinecarboxylic acid) applied to leafy spurge also was correlated $(\mathrm{r}=0.97)$ with field results.
\end{abstract}

\footnotetext{
${ }^{1}$ Received for publication Sept. 11, 1987, and in revised form Dec. 4, 1987.

${ }^{2}$ Letters following this \# symbol are a WSSA-approved computer code from Composite List of Weeds, Weed Sci. 32 , Suppl. 2. Available from WSSA, 309 W. Clark St., Champaign, IL 61820.
} 


\section{Additional Words:}

Weed simulation model, sensitivity analysis, EPHES.

\section{Introduction}

Harper and Sagar (7) suggest an approach for conducting weed research that involves focusing control tactics on vulnerable points in the life cycle of weed species. They state: "A detailed knowledge of a plant life cycles can show the 'achilles heel' of each weed species and allow control measures to be directed most efficiently." Population simulation models prove useful to identify the "achilles heels" of weed species and to evaluate weed control tactics.

Leafy spurge, a herbaceous perennial weed of range and pasture lands, is most common in the northern Great Plains of the United States and southern provinces of Canada (6). Leafy spurge grows in many habitats, including xeric to subhumid climates and fine to coarse soils. It grows in open grasslands or under forest canopies (20). There are no herbicides, applied as a one-time treatment, or biological controls that will provide effective and environmentally acceptable, long-term control of leafy spurge.

Since weed control practices generally are directed at weed populations, weed biology models should estimate plant population behavior (13). Several researchers have studied the population dynamics of leafy spurge $(3,4,20,22)$. The objective of this study was to demonstrate how the process of developing population growth simulation models, using leafy spurge as an example, can be useful for evaluating weed development and control measures.

\section{Model development}

\section{The first-generation model}

Watson (22) divided the life history of leafy spurge into five stages: seeds, root buds, seedlings, vegetative shoots, and flowering shoots. By identifying these stages and the processes of the population was formed (Figure 1). Conversion of state variables (boxes) shown in the diagrammatic model to actual values and development of equations that describe flow rates (valves) between life history stages follow organization of the conceptual framework. An efficient way to summarize the mathematical relationships depicted diagrammatically in Figure 1 is by a transition matrix $(9,10,19,23)$. Watson (22) used a transition matrix model initially to describe the population dynamics of leafy spurge. This approach also has been used successfully to develop other weed population models (5, $13,14,18)$.

An important step in developing transition matrix models is forming a column vector. In this study's leafy spurge model, the column vector, $\mathrm{N}$, represents the number of plants in each stage of the population: 


$$
\mathrm{N}=\left[\begin{array}{l}
\text { Number of seeds } \\
\text { Number of basal buds } \\
\text { Number of seedlings } \\
\text { Number of vegetative shoots } \\
\text { Number of flowering shoots }
\end{array}\right]
$$

The values in the column vector change as population size and structure change over time.

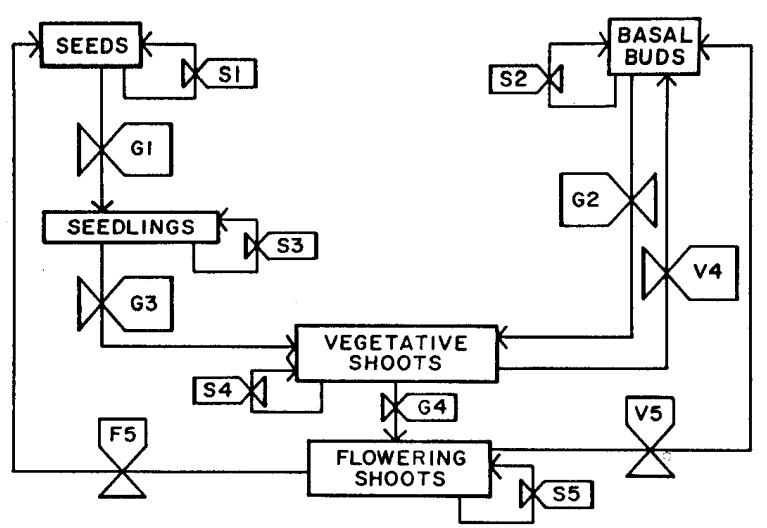

Figure 1. Diagrammatic model of a leafy spurge population: the boxes represent stages in the life cycle, arrows indicate processes, valve symbols represent the rate at which a process occurs over a specified iteration time.

\section{Model transition parameters:}

$\mathrm{S1}=$ proportion of seeds that remain viable in the seed bank

$\mathrm{S} 2=$ proportion of basal buds that remain viable

$\mathrm{S3}=$ proportion of seedlings that remain seedlings

$\mathrm{S} 4=$ proportion of vegetative shoots (non-flowering mature) that remain vegetative

S5 $=$ proportion of flowering shoots that remain flowering

G1 = proportion of seed that germinates to become seedlings

G2 = proportion of basal buds that grow to vegetative shoots

F5 = number of seeds produced per flowering shoot

V4 = number of buds produced per vegetative shoot

V5 = number of buds produced per flowering shoot

The number of individuals in each life history stage depends on the rate new individuals graduate into a stage and the rate at which individuals graduate to another stage or die (Figure 1). For example, the number of seeds in a population depends on the rate flowering shoots produce seeds, the ability of seeds to survive, and the rate at which seeds germinate and become seedlings. Thus, the number of individuals present in different stages is governed by the transition of individuals from one stage to another. 
The transition matrix summarizes the rates of transition between life history stages for an entire plant population. The transition matrix, M, for the leafy spurge model (Figure 1) is represented by

$$
\mathrm{M}=\left[\begin{array}{lllll}
\mathrm{S} 1 & 0 & 0 & 0 & \mathrm{~F} 5 \\
0 & \mathrm{~S} 2 & 0 & \mathrm{~V} 4 & \mathrm{~V} 5 \\
\mathrm{G} 1 & 0 & \mathrm{~S} 3 & 0 & 0 \\
0 & \mathrm{G} 2 & \mathrm{G} 3 & \mathrm{~S} 4 & 0 \\
0 & 0 & 0 & \mathrm{G} 4 & \mathrm{~S} 5
\end{array}\right]
$$

In this transition matrix, the values $\mathrm{S}$ through $\mathrm{S} 5$ are the survival rates or the proportion of the individuals that remain in the same stage. F5 represents the production of seeds by flowering shoots. V4 and V5 are the production rates of basal buds on vegetative and flowering shoots, respectively. G1 through G4 are the rates at which individuals graduate from one stage to another. Zero values mean no transition between stages is possible, e.g., basal buds do not produce seeds. Columns in the matrix show the fate of individuals starting at each of the five life history stages of leafy spurge. Rows in the matrix correspond to life history stages that result at a subsequent observation time $(\mathrm{t})$ and show the sources of individuals in the population.

The transition matrix and the population column vector are combined through matrix algebra to create a succinct description of population changes over time:

$$
\mathbf{N}(\mathrm{t}+1)=\mathbf{M N}(\mathrm{t})
$$

This equation indicates at the next observation time $(\mathrm{t}+1)$, the population size and number of individuals in each life history stage $[\mathbf{N}(\mathrm{t}+1)]$ is a result of the transitions $(\mathbf{M})$ of individuals contained in life history stages at the current time $[\mathbf{N}(\mathrm{t})]$. If the transition rates and population sizes are determined accurately, the procedure should predict future plant population size.

Watson (22) obtained values from the literature for six transition matrices representing developmental periods of leafy spurge for a year. This detail allowed six growth periods over a year rather than the single annual time increment. Therefore, six transition matrices were developed in the Watson (22) model, and the number of parameters (values in transition matrix greater than zero) increased from 12 to 29.

However, the transition matrix model just described predicts exponential population growth because the transition parameters in the matrix are constant. This observation occurs rarely in most natural stands of leafy spurge and other plants. The transition rates between sizes and life history stages of populations generally are not constant over time. Different plant densities, genetic variability, weather patterns, seasons of growth, and management tactics all suggest that transition matrices should be dynamic. In other words, the transition element values in these models should vary according to different conditions of the biotic and abiotic environment. 


\section{The second-generation model}

Developing the second-generation model focuses on how biotic and abiotic factors affect each transition parameter in the matrix and incorporates these effects into the model. However, there always are many transitions to study (22). Sensitivity analysis is a method used to rank the transitions for further study.

Sensitivity analysis is conducted by changing the value of a parameter in the model that describes a particular transition, while keeping all other transition parameters constant. The population size (model output) is determined. A sensitivity value, i.e., the ratio of proportional change in simulated output to the proportional change of the transition parameter, can be calculated:

$$
\text { Sensitivity value }=\frac{\Delta \text { output }}{\text { output }} / \frac{\Delta \text { parameter }}{\text { parameter }}
$$

Large sensitivity values mean that small adjustments in a transition parameter cause large changes in model output. Thus, critical parameters are identified in the model for further study because they have disproportionally large effects on weed population size and suggest possible points of vulnerability of the weed species.

Three transitions in life history influenced the total number of leafy spurge shoots based on a sensitivity analysis of the Watson (22) model: bud transition to vegetative shoots during the germination period (G2), survival of vegetative shoots in the establishment stage (S4), and survival of buds over the winter (S2) (Table 1 and Figure 1).

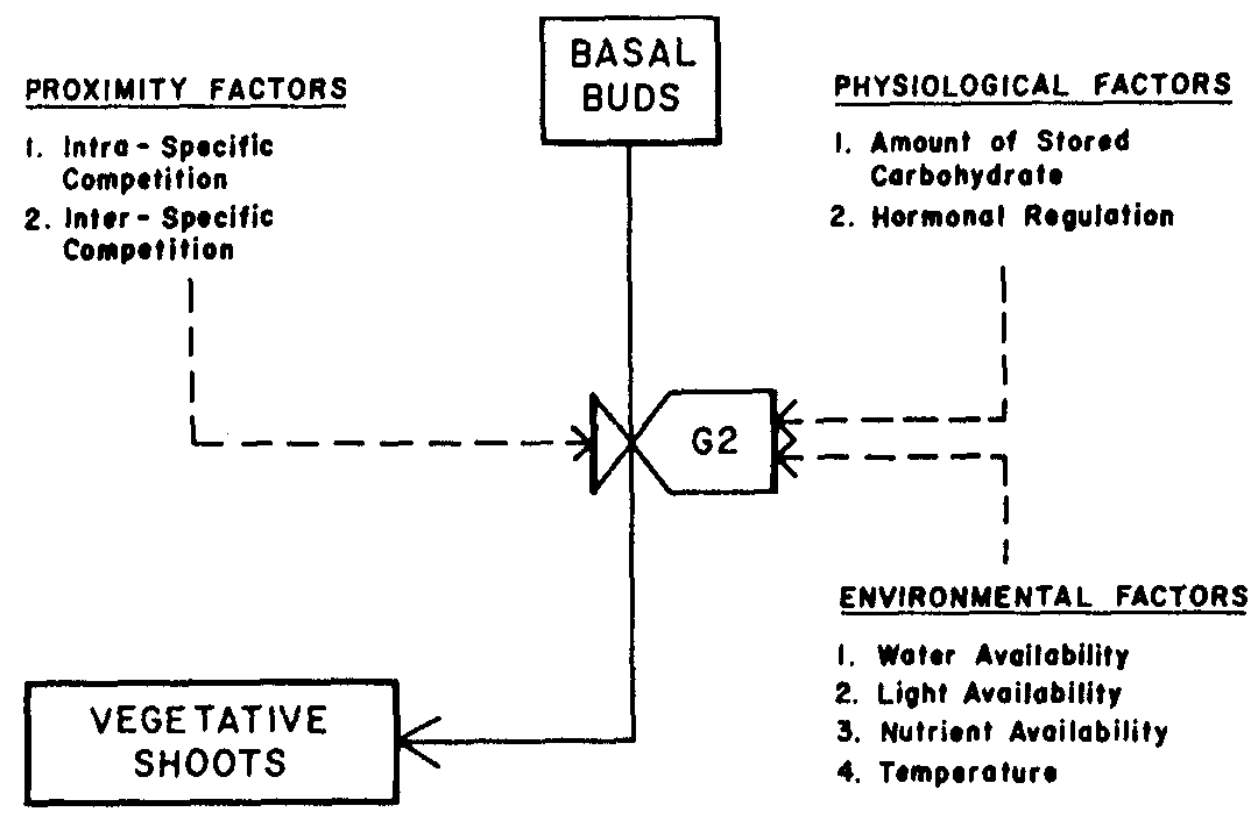

Figure 2. Diagrammatic submodel of the leafy spurge population model including factors believed to influence basal bud transition to vegetative shoots. 
Table 1. The sensitivity of leafy spurge population size resulting from a 10 and $20 \%$ decrease in each transition parameter in the six developmental period matrices of the first generation model after a 10-year simulation time. Asterisks mark the three transitions with the largest sensitivity values.

\begin{tabular}{|c|c|c|c|}
\hline \multirow[b]{2}{*}{ Developmental period } & \multirow[b]{2}{*}{ Parameter } & \multicolumn{2}{|c|}{ Change in parameter } \\
\hline & & $-10 \%$ & $-20 \%$ \\
\hline & & -( & ) \\
\hline \multirow[t]{4}{*}{ Germination } & G1 & 0.14 & 0.17 \\
\hline & $\mathrm{G} 2 *$ & 6.30 & 4.38 \\
\hline & $\mathrm{S} 1$ & 0.01 & 0.01 \\
\hline & S2 & 0.38 & 0.37 \\
\hline \multirow[t]{5}{*}{ Establishment } & G3 & 0.14 & 0.17 \\
\hline & S1 & 0.01 & 0.01 \\
\hline & S2 & 0.38 & 0.37 \\
\hline & $\mathrm{S} 3$ & 0.00 & 0.00 \\
\hline & $\mathrm{S} 4 *$ & 6.30 & 4.38 \\
\hline \multirow[t]{5}{*}{ Development } & G4 & 3.00 & 2.58 \\
\hline & S1 & 0.01 & 0.01 \\
\hline & S2 & 0.38 & 0.37 \\
\hline & S3 & 0.00 & 0.00 \\
\hline & S4 & 4.69 & 3.64 \\
\hline \multirow[t]{5}{*}{ Maturation } & S1 & 0.01 & 0.01 \\
\hline & S2 & 0.38 & 0.37 \\
\hline & $\mathrm{S} 3$ & 0.00 & 0.00 \\
\hline & S4 & 4.69 & 3.64 \\
\hline & S5 & 3.00 & 2.58 \\
\hline \multirow[t]{8}{*}{ Reproduction } & F5 & 0.10 & 0.10 \\
\hline & V4 & 4.30 & 3.44 \\
\hline & V5 & 2.66 & 2.34 \\
\hline & S1 & 0.01 & 0.01 \\
\hline & S2 & 0.38 & 0.37 \\
\hline & S3 & 0.00 & 0.00 \\
\hline & S4 & 0.64 & 0.64 \\
\hline & S5 & 0.36 & 0.36 \\
\hline \multirow[t]{2}{*}{ Over winter } & S1 & 0.11 & 0.11 \\
\hline & $\mathrm{S} 2 *$ & 6.08 & 4.31 \\
\hline
\end{tabular}


Possible mechanisms governing the transition from leafy spurge root buds to vegetative shoots were divided into proximity, physiological, and environmental factors (Figure 2). These factors represent different levels of complexity and are likely to interact in their effect on bud transition to vegetative shoots. For example, the effect of density, a proximity factor, on population development results from competition for resources. Environmental factors dictate levels of resources available to plants and often the physiological status of plants. Therefore, a hierarchy of factor types was established which indicates the progression of detail in the resulting second-generation model. The influence of competition was added first to the model, followed by physiological and environmental factors. Management factors also influence transition rates and will be considered later.

The inherent genetic variability in leafy spurge is an additional factor that should be included in a third-generation model. However, since there is little published information about the distribution of genotypes, rate of genetic change, or how genetic variability specifically influences control practices, it may be included in the model as a stochastic process where the initial transition rates can be chosen at random from the observed distribution of rates associated with each process.

Increased density of clonal species is negatively correlated with the number of individuals arising from "vegetative" reproduction $(1,8,21)$. Therefore, the number of propagules (buds) produced on leafy spurge plants was believed to decrease according to a functional relationship with increasing density. A simple linear relationship between bud transition and total shoot density illustrates the potential role of density-dependent factors on the population size of leafy spurge (Figure 3).

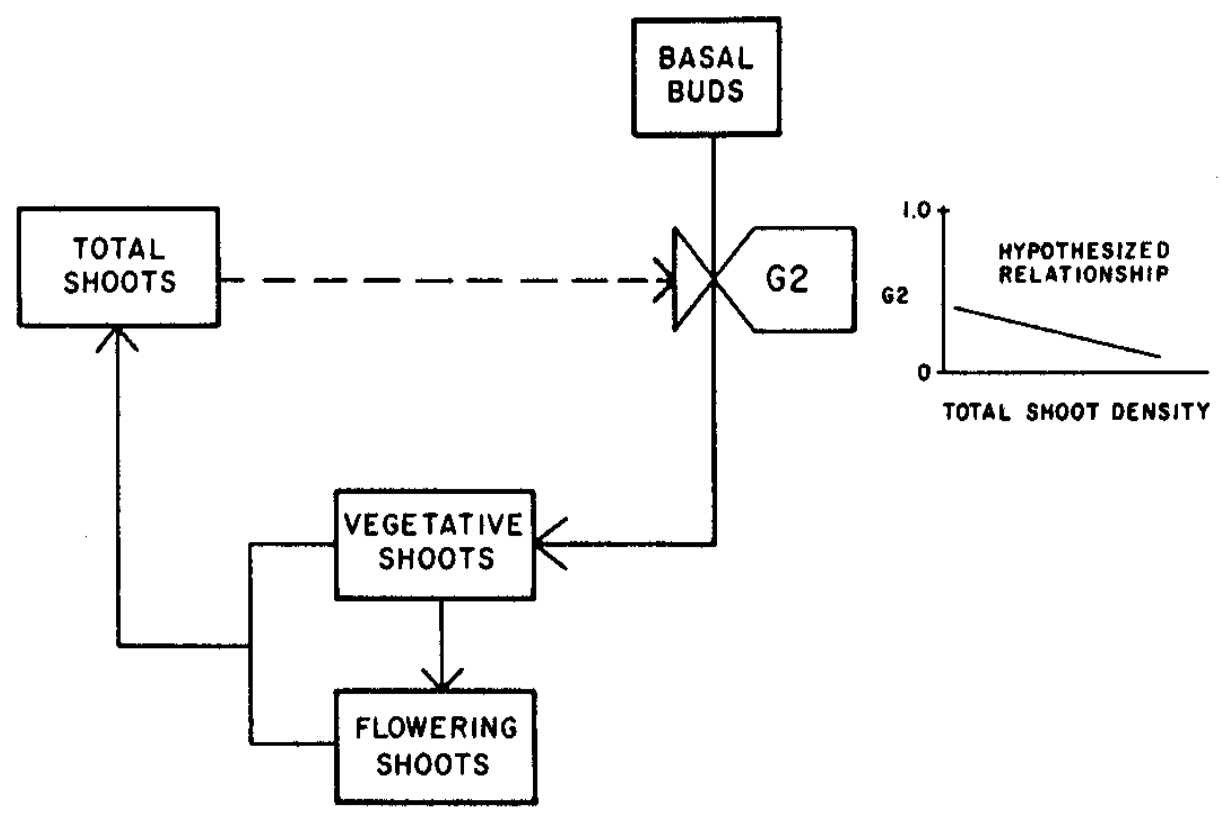

Figure 3. Diagrammatic submodel of the leafy spurge population model showing how total stem (intraspecific) density influences basal bud transition to vegetative shoots and a graphic representation of the relationship between root bud transition rate and total stem density.

Page 7 of 12 
Environmental factors may be the preferred level of complexity to base mechanisms that drive processes in plant populations because environment influences most physiological factors. McIntyre (11) proposed that internal competition between buds for water could influence leafy spurge root bud growth. A functional relationship between available soil water and bud transition is shown in Figure 4.

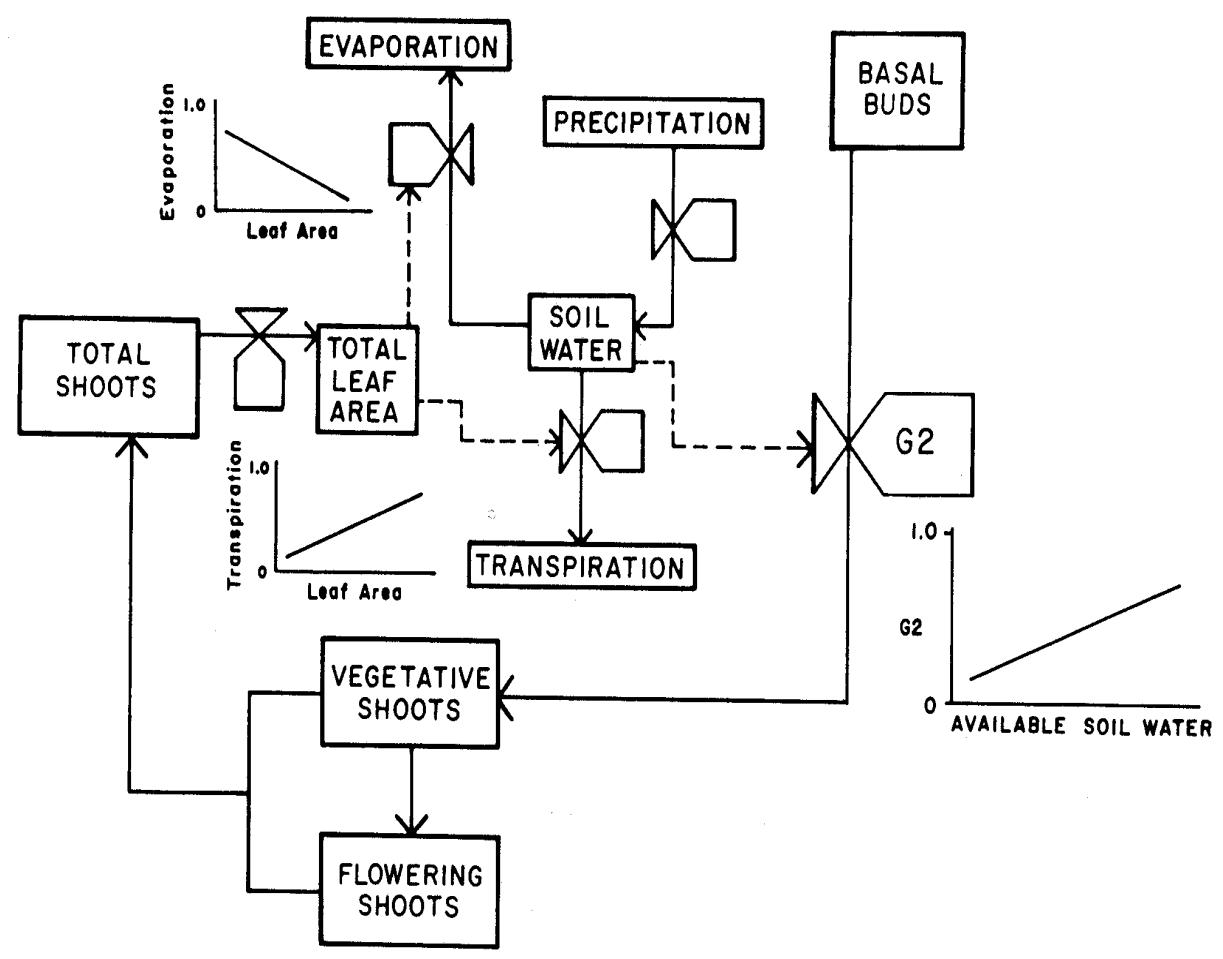

Figure 4. Diagrammatic submodel of a leafy spurge population which includes the influence of available water on the transition rate from basal buds to vegetative shoots and factors that influence the amount of available soil water to plants (parameters not included in the second-generation model were not named) (see text).

Physiological effects on root bud transition include stored carbohydrate availability and hormonal regulation (15). Leafy spurge root carbohydrate levels tend to follow an annual pattern that is predictable by phenological stage of the plants (12). Raju (16) and Raju and Marchuk (17) reported that vascular induction, immediately preceding bud growth, coincides with increased soluble carbohydrates in leafy spurge roots. Therefore, functional relationships between bud transition and carbohydrate and hormone levels also could be incorporated into the model.

The relationship between resources and bud transition was developed by incorporating both plant proximity and certain environmental factors into the model. The processes of evaporation, transpiration, and precipitation influence plant-available soil water. Leaf area can influence the rate of evaporation and transpiration, which in turn is a function of the total number of shoots. This addition of factors and processes shows the integration of several levels of biological complexity into the model (Figure 4). 


\section{Model simulation}

Leafy spurge population growth was simulated with the second-generation model that included intraspecific density-dependent functions on the three important transition parameters: basal buds to vegetative shoots (G2), the number of basal buds flowering shoots produce (V5), and the number of basal buds vegetative shoots produce (V4). Simulation results for density dependence on each transition parameter separately produced exponential growth similar to that predicted by the first-generation model (22).

When density-dependent functions for the three transition parameters were included in the model simultaneously, initial exponential growth occurred followed by growth decline and stabilization of the simulated population (Figure 5). These simulations indicated the importance of intraspecific density on population growth of leafy spurge and a need to test this relationship experimentally.

\section{Model validation}

An independent process of model validation can be used to determine the level of simulation accuracy by monitoring a natural population and by comparing the results with those from the model. Research incorporating the models should provide a means of validation, which could be a continuous and integral part of refining the model. When specific experiments are established to determine transition rates or relationships between influencing factors and transitions, a portion of the data can be retained for validation of the population models.

\section{Using the model for weed management}

Using weed population models to evaluate management tactics usually follows the processes of refinement and validation. Sensitivity analysis and subsequent refinement of important transition parameters can identify potential points of vulnerability in a weed population (Table 1 and Figures 1 through 4).

Management strategies can be assessed directly with this leafy spurge population model by introducing the effect of a control practice. The effects of picloram and a foliage-feeding herbivore were evaluated with the second-generation model that contained the density-dependent functions (Figure 5). A single application of picloram in the spring of Year 10 was simulated by removing $95 \%$ of the leafy spurge stems the first year, $85 \%$ the second year, and $60 \%$ the third year (Figure 6). The second- and third-year removals coincided with residual effects of the herbicide observed in field experiments (2). The simulated results match closely $(r=0.97, p<0.001, n=6)$ the response curve of field observations.

Page 9 of 12 


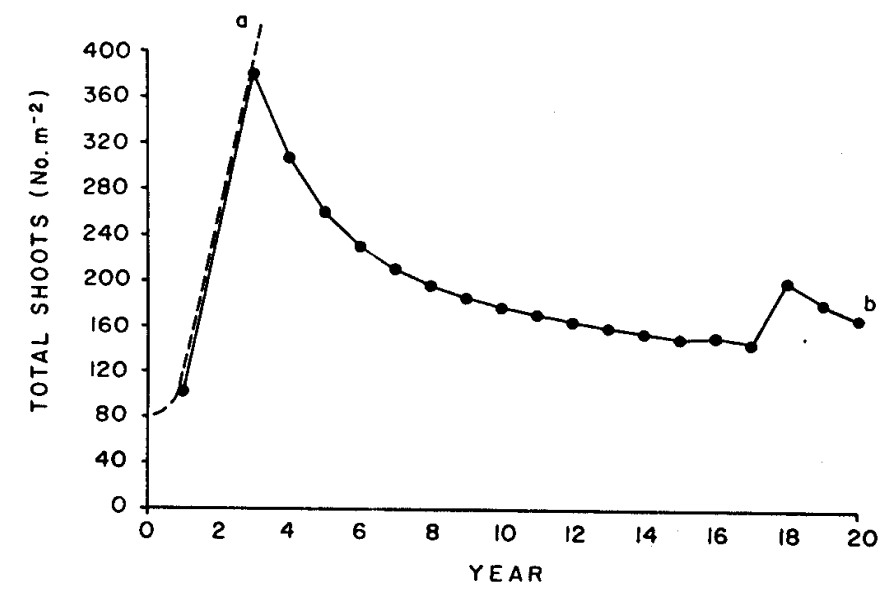

Figure 5. a. Leafy spurge population growth simulation with no density-dependent functions included in the model. b. Population growth simulation with density-dependent functions included in the model on transition of basal buds to vegetative shoots (G2), basal buds produced by flowering shoots (V5), and basal buds produced by vegetative shoots (V4).

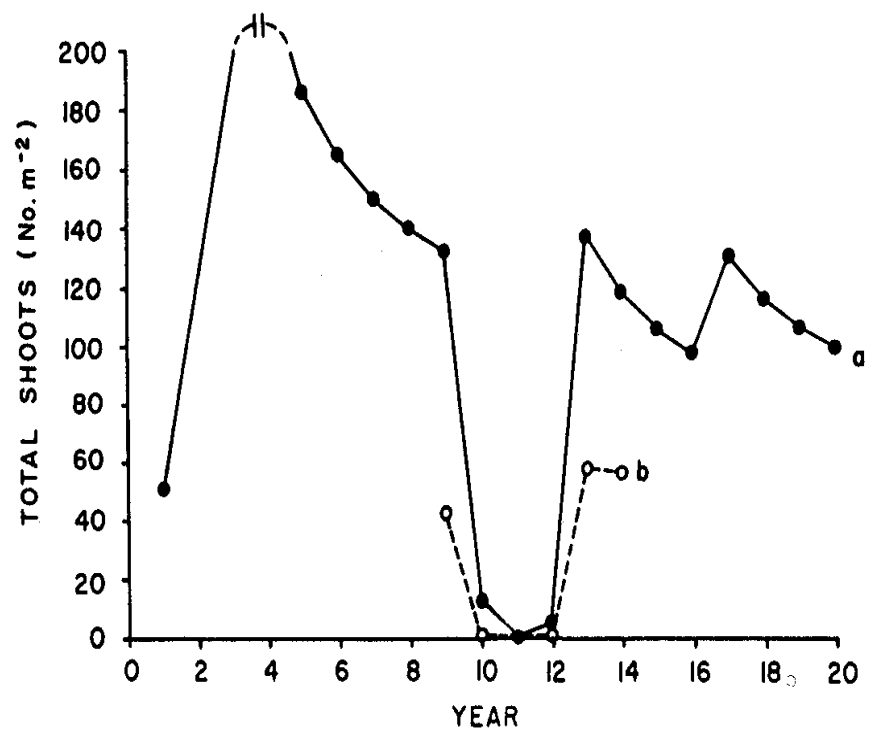

Figure 6. a. Leafy spurge population simulation with density-dependent functions and a single application of picloram simulated at Year 10. b. Observed results of a picloram application (2).

The effect of a foliage-feeding herbivore introduced on a leafy spurge population at Year 10 also was simulated by removing 40, 50, and $60 \%$ of the stems every year after introduction (Figure 7). These simulations of biological control show how the model can determine the amount of leafy spurge control required to decrease and to maintain the weed population at a low level. 


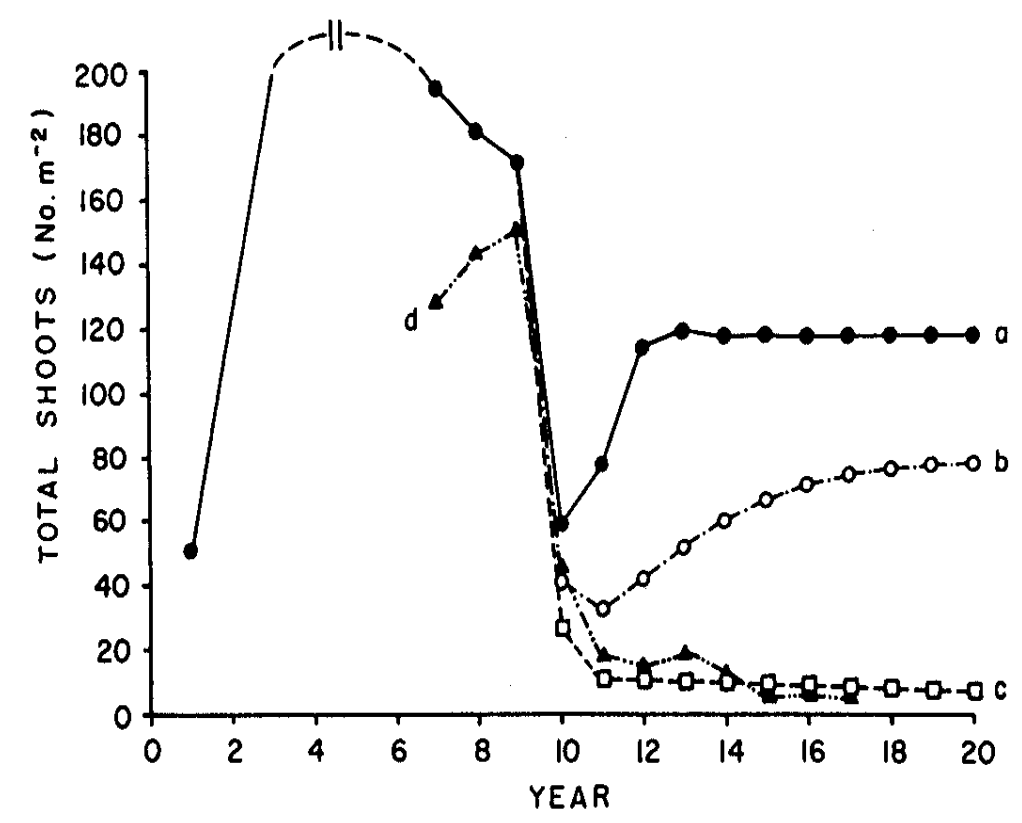

Figure 7. Leafy spurge population simulation with density-dependent functions simulating the introduction of a foliage-feeding herbivore at Year 10 that removes (a) 40, (b) 50, and (c) 60 percent of the stems. Also shown $\operatorname{arc}(d)$ observed results of sheep feeding on leafy spurge(4).

Cattle will not graze forage growing in dense stands of leafy spurge (22). If a density threshold of leafy spurge were determined at which cattle would graze the forage, the model could predict the level of control required to maintain the population below that threshold density. Alternatively, the model could be used to manage leafy spurge for sheep forage. Observed data from a field experiment (4) where sheep were used to control leafy spurge corresponds to the simulation in which $60 \%$ of the stems were removed (Figure 7). The accuracy of the simulation $(\mathrm{r}=0.98, \mathrm{p}<0.001, \mathrm{n}=11$ ) was surprising considering the simplicity of the functions in the model used to control population growth. These examples show the types of analysis possible with a model to identify critical population growth-regulating transitions and how these transitions should be focused to assess the value of current control practices and development of new control strategies.

Demonstrating the progression of model construction with leafy spurge shows how the modeling approach can be used to apply basic biological information to develop weed control strategies. Models can help to organize existing information and to provide a structure to identify where important information is needed. The process also can identify points of vulnerability in the weed population and can allow a better understanding of how weed population growth is regulated. 


\section{Literature cited}

1. Abrahamson, W. G. 1980. Demography and vegetative reproduction. p. 89-106 in: O. T. Solbrig, ed. Demography and Evolution in Plant Populations. Univ. Calif. Press, Berkley.

2. Bowes, G. G. and E. S. Molberg. 1975. Picloram for the control of leafy spurge. Can. J. Plant Sci. 55:1023-1027.

3. Bowes, G. G. and A. G. Thomas. 1978. Leafy spurge (Euphorbia esula L.) control based on a population model. Proc. 1st, Int. Rangeland Congr., p. 254-256.

4. Bowes, G. G. and A. G. Thomas. 1978. Longevity of leafy spurge seed in the soil following various control programs. J. Range Manage. 31:137-140.

5. Cousens, R. D. 1986. The use of population models in the study of the economics of weed control. Proc. European Weed Res. Soc. Symp. 1986. Econ. Weed Control, p. 269-276.

6. Dunn, P. H. 1985. Origins of leafy spurge in North America. p. 7-13 in: A. K. Watson, ed. Leafy Spurge. Weed Sci. Soc. Am., Champaign, IL.

7. Harper, J. L. and G. R. Sagar. 1953. Some aspects of the ecology of buttercups in permanent grasslands. Proc. Br. Weed Control Conf. 1:256-265.

8. Holler, L. C. and W. C. Abrahamson. 1977. Seed and vegetative reproduction in relation to density in Fragaria virginiana (Rosaceae). Am. J. Bot. 64:1003-1007.

9. Lefkovitch, L. P. 1967. A theoretical evaluation of population growth after removing individuals from some age groups. Bull. Entomol. Res. 57:437-445.

10. Leslie, P. H. 1945. On the use of matrices in certain population mathematics. Biometrika 33:183-213.

11. McIntyre, G. I. 1979. Developmental studies on Euphorbia esula. Evidence of competition for water as a factor in the mechanism of root bud inhibition. Can. J. Bot. 57:2572-2581.

12. Messersmith, C. G. 1983. The leafy spurge plant. N. D. Farm Res. 40(5):3-7.

13. Mortimer, A. M. 1983. On weed demography. p. 3-40 in: W. W. Fletcher, ed. Recent Advances in Weed Research. Commonwealth Agricultural Bureaux, England.

14. Mortimer, A. M., D. J. McMahon, R. K. Manlove, and P. D. Putwain. 1980. The prediction of weed infestations and cost of differing control strategies. In: Proc. 1980 Br. Crop Prot. Conf.-Weeds.: 415-423.

15. Nissen, S. J. and M. E. Foley. 1987. Correlative inhibition and dormancy in root buds of leafy spurge (Euphorbia esula). Weed Sci. 35:155-159.

16. Raju, M.V.S. 1975. Experimental studies on leafy spurge (Euphorbia esula L.) I. Ontogeny and distribution of buds and shoots on the hypocotyl. Bot. Gaz. 136:254-261.

17. Raju, M.V.S. and W. N. Marchuk. 1977. Experimental studies on leafy spurge (Euphorbia esula L.) III. Xylem development in relation to the hypocotylary bud growth. Bot. Gaz. 138:264-261.

18. Sagar, G. R., and A. M. Mortimer. 1976. An approach to the study of the population dynamics of plants with special reference to weeds. Ann. Appl. Biol. 1:1-47.

19. Sarukhan, J. and M. Gadgil. 1974. Studies on plant demography: Ranuculus repens L., R. bulbosus L. and $R$. acris L. III. A mathematical model incorporating multiple modes of reproduction. Ecol. 62:921-936.

20. Selleck, G. W., R. T. Coupland, and C. Frankton. 1962. Leafy spurge in Saskatchewan. Ecol. Monogr. 32:1-29.

21. Thomas, A. G. and H. M. Dale. 1975. The role of seed reproduction in the dynamics of established populations of Hieracium floribundum and a comparison with that of vegetative reproduction. Can. J. Bot. 53:3022-3031.

22. Watson, A. K. 1985. Integrated management of leafy spurge. p. 93-104 in: A. K. Watson, ed. Leafy Spurge. Weed Sci. Soc. Am., Champaign, IL.

23. Werner, P. A. and H. Caswell. 1977. Population growth rates and age versus stage-distribution models for teasel (Dipsacus sylvestris Huds.). Ecol. 58:1103-1111. 